\title{
La historiografía reciente de la justicia en México, siglo XIX: perspectivas, temas y aportes ${ }^{1}$
}

\author{
Mirian Galante \\ CCHS, CSIC \\ mirian.galante@cchs.csic.es
}

Recepción: 21 de marzo de 2011 / Revisión: 26 de abril de 2011

Aceptación: 9 de junio de 2011 / Publicación: diciembre de 2011

\section{RESUMEN}

La historiografía sobre la justicia en la conformación de los Estados modernos en occidente se encuentra en estos momentos en plena ebullición. El objetivo de este artículo es recoger algunas de las aportaciones más recientes sobre la historia de la justicia en México en el período comprendido entre el proceso emancipador y la revolución de 1910. En él se apuntan las principales influencias teóricas, perspectivas analíticas y temáticas de trabajo desarrolladas en este ámbito desde la historia del derecho y desde la historia social. La reformulación que estos trabajos plantean sobre la concepción del Estado, de la sociedad civil y de relación entre ambos, a través de la ley y de las prácticas judiciales, contribuye a repensar el proceso de construcción política del Estado mexicano en el siglo XIX.

Palabras clave: Historiografía, Derecho, Justicia, Cultura jurídica, México, siglo XIX.

\section{Current Historiography on Law and Justice in Mexico, $19^{\text {th }}$ Century: Perspectives, Issues and Contributions}

\begin{abstract}
Historiography regarding the role of Justice in the formation of modern states in the Western World is currently in a period of effervescence. This paper aims to analyse the latest contributions on the History of Justice in Mexico between the Emancipation process and the 1910 Revolution, reviewing main theoretical influences, analytical perspectives, and subjects of study developed in the History of Law, from the perspective of Social History. These works contribute to the rethinking of the process of political construction of the 19th Century Mexican State, introducing a new way to think about the state itself, civil society, and the relationship between both, through law and judicial practice.
\end{abstract}

Keywords: Historiography, Law, Justice, Legal Culture, Mexico, $19^{\text {th }}$ Century.

SUMARIO: 1. Introducción. 2. De la historia del derecho a la historia de la cultura jurídica. 3. La visión de la justicia desde la historia social. 4. Consideraciones finales. 5. Referencias bibliográficas.

\section{INTRODUCCIÓN}

La historiografía mexicanista sobre la historia de la justicia se encuentra en estos momentos en una etapa de revisión y de repunte; se están gestando cambios interesantes, gracias a la reubicación de los focos de interés en las investigaciones, la

${ }^{1}$ Este trabajo se inscribe en el proyecto I+D HAR2010-17580. 
profusión de perspectivas analíticas, la definición de nuevas temáticas, el estudio de fuentes heterogéneas y la consulta de archivos poco transitados por los historiadores. Aunque aún faltan más resultados y expresiones de dichos cambios, a estas alturas ya puede constatarse que las aportaciones y revisiones de esta proliferación de estudios están afectando no solo a la historia jurídica y judicial, sino también a la historia social y a los trabajos históricos sobre la cultura política e institucional del país.

La atención a la historia jurídica mexicana no es exclusivamente reciente, sino que contamos con una producción relevante sobre esta temática que ha marcado directrices sin las cuales no podría comprenderse la discusión actual. Si la tradición de editar materiales jurídicos ha facilitado el acceso a fuentes doctrinales e ideológicas, al hilo de la interpretación de los procesos de construcción de los códigos y de la definición de las instituciones se han forjado conceptos que siguen vigentes en los debates recientes. Por último, cabe destacar igualmente que algunos de los historiadores y juristas "clásicos" están fomentando y/o dinamizando la creación de espacios de reflexión e intercambio en los cuales se está produciendo esta renovación ${ }^{2}$.

En los últimos tiempos la reactivación del interés por la historia del derecho y de la justicia ha venido acompañada de una reorientación en sus aproximaciones a estos temas debida, en gran medida, al giro cultural experimentado a fines de 1980, que ha afectado, respectivamente, al derecho y a la historia como disciplinas. La comprensión del derecho como "fenómeno social" ha adquirido una doble dimensión: atendiendo a su capacidad para impulsar, modificar, contener o restringir las dinámicas sociales y ser afectado por ellas; y también considerando la producción del derecho, su interpretación y su aplicación como un proceso social en sí mismo. Por su parte, la atención a la sociedad, en su heterogeneidad y diversidad, como actor fundamental en la conformación jurídico política del Estado nación se inserta en una mirada relacional que recompone la interacción entre la sociedad y el Estado desde una perspectiva procesual. Todo ello ha permitido definir un campo de exploración, en parte inédito, en el que se entrecruzan las miradas de juristas, historiadores, antropólogos, politólogos y sociólogos ${ }^{3}$.

En los trabajos históricos actuales se cuestiona la identificación totalizadora entre ley y derecho, se matiza la consideración monolítica de la primera como instrumento (legítimo y legitimador) de la autoridad del Estado, se reconocen espacios de interpretación de los agentes encargados de su administración, se destaca su capacidad de

${ }^{2}$ Una buena aproximación a las transformaciones experimentadas en las últimas décadas en la escuela "mexicana" de historiadores del derecho, atendiendo a sus antecedentes, a sus principales actores, instituciones, líneas de investigación y producciones, en Del ArenAl, 2006a, pp. 57-76; sobre la influencia de historiadores extranjeros en la historia del derecho en México, Del Arenal, 2006b, pp. 1467-1495.

${ }^{3}$ La repercusión de las obras de Clifford Geertz, E.P. Thompson, Michel Foucault o Pierre Bourdieu en la antropología, la historia o la sociología se han entrecruzado con las propias transformaciones experimentadas en el campo jurídico, en ámbitos como la sociología jurídica o la teoría jurídica crítica. Sobre la sociología jurídica Deflem, 2008; Banakar, 2005, pp. 58-73; Cotterrell, 2008; algunas de las propuestas más significativas de los "Critical Legal Studies" en Hutchinton, 1989; Helman, 1987; Pérez Lledó, 1996. Una buena aproximación a las consecuencias de estas transformaciones en la historia del derecho: HesPanHa, 2002. 
adaptación a distintas coyunturas sociopolíticas, así como su potencial para incorporar significaciones y demandas de distintos grupos sociales afectados por su aplicación. Todo ello ha contribuido a complejizar la mirada histórica sobre la relación entre la ley y el derecho, entre la ley y el Estado (y el ejercicio del poder) o entre la ley y la sociedad. Actualmente se entienden como relaciones multidireccionales de continua negociación que afectan a la propia comprensión de cada uno de los elementos implicados. Elementos que, a su vez, han sido igualmente replanteados teórica e historiográficamente 4 .

Este trabajo analiza algunos de los estudios recientes más relevantes sobre la historia de la justicia en México en el período comprendido entre la independencia y la revolución de 1910, dedicando especial atención a la justicia penal ${ }^{5}$. Su objetivo no es hacer una enumeración exhaustiva de la ingente literatura existente, sino apuntar las líneas de trabajo actuales, sus aportes y sus posibles proyecciones hacia el futuro, siguiendo los dos principales ámbitos desde los que se ha abordado esta cuestión, esto es, desde la historia jurídico-política y desde la historia social.

La primera aborda el proceso de reorganización de los poderes y su administración en el diseño y consolidación del Estado liberal desde distintas perspectivas: atendiendo a la confección de su legislación -con especial atención a las constituciones- y sus instituciones; a la legitimación académica, social y profesional de los agentes de la administración de justicia, y a las prácticas judiciales entendidas como momentos en los que se actualizan los imaginarios sociales sobre la justicia, se activa el protagonismo de los intermediarios y jueces, la legislación cobra materialidad y significación, y se ponen en funcionamiento los procedimientos y dispositivos judiciales. En este rubro se insertan trabajos de distinta naturaleza, como los adscritos a la historia crítica del derecho, los implicados en los estudios sobre la definición de cuerpos de profesionales o aquellos que se nutren de una historia especialmente interesada en la recomposición de los imaginarios sociales. La mayoría de ellos, aunque como veremos no todos, se concentran en el análisis de la primera mitad de siglo.

La segunda se interesa por la "reorganización y normalización de la sociedad" que se pretendió en el siglo XIX y atiende a la interacción entre el mundo jurídico y judicial y los actores sociales, ya sean individuales y colectivos, desde perspectivas multidireccionales que reconstruyen las dinámicas de negociación entre el Estado y la sociedad y las consecuencias que éstas tienen para ambos. Dedicados principalmente a la segunda mitad del siglo XIX, ponen de relieve la variedad de los actores implicados así como la diversidad de estrategias e intensidades de su respuesta ante las acciones legales del Estado. Desde la segunda se matizan y complementan, a partir de numerosos estudios de caso, algunas de las reflexiones de los primeros.

${ }^{4}$ Entre los trabajos históricos colectivos dedicados a todo el ámbito latinoamericano en los que se aprecian estas transformaciones: Zimmermann (ed), 1999; Salvatore - Aguirre - Gilbert, 2001; Aguirre - Buffington (eds.), 2000; Palacio - Candioti (comp.), 2007.

${ }^{5}$ Para una reflexión sobre la producción reciente de la historiografía jurídica mexicanista sobre este mismo período, resulta sumamente clarificador MiJANGOS y GoNZÁLEZ, 2011. 


\section{DE LA HISTORIA DEL DERECHO A LA HISTORIA DE LA CULTURA JURÍDICA}

Los debates producidos en las últimas décadas en el seno de la teoría y la filosofía jurídicas han tenido una fuerte impronta en el desarrollo de la historiografía jurídica mexicanista del siglo XIX. Especialmente la reacción contra el formalismo jurídico y el desarrollo de las doctrinas institucionistas, realistas y sociológicas ${ }^{6}$ han configurado un nuevo panorama orientado a restablecer los lazos entre la sociedad y el derecho. La comprensión del fenómeno jurídico se inserta en la realidad social en la que es conceptualizado, producido y aplicado, lo que desde una crítica mirada histórica ha permitido reconstruir los distintos órdenes jurídicos existentes en el seno de una misma tradición cultural. Gracias a estas reformulaciones de juristas e iushistoriadores se han realizado aportes significativos que han contextualizado el proceso histórico mediante el cual el derecho fue reduciéndose al derecho estatal y la ley se fue consolidando como el único modo de creación del derecho. El desarrollo, discusión y aplicación del concepto de cultura jurídica ha incentivado la ampliación del objeto de estudio, ha fomentado el enfoque multidisciplinar, y ha enfatizado la necesidad de contextualizar los procesos normativos en lugar de asumir la naturalización de la ley. Todo ello ha complejizado los análisis, al incorporar otras dimensiones del derecho profundamente relacionadas con aspectos culturales, sociales y políticos ${ }^{7}$.

En el marco de esta historia del derecho comprendida como un proceso social en sí misma y dedicada al estudio de la formación jurídico institucional del Estado mexicano pueden apuntarse tres grandes bloques temáticos: la inserción de la justicia en el orden constitucional liberal, los actores del derecho y las prácticas judiciales.

En consonancia, con las revisiones historiográficas que se vienen produciendo en la historia política y la historia social, la literatura jurídico-institucional está mostrándose especialmente interesada por analizar cómo se insertó la justicia en la reordenación de los poderes acontecida como consecuencia de la crisis monárquica de 1808 . En torno a esta cuestión pueden apreciarse dos líneas de trabajo: una que, destacando los elementos de continuidad con el orden del Antiguo Régimen, confiere a la justicia la centralidad en la significación y el sentido del poder político, y otra que aborda la conformación de la justicia en relación con la construcción de los demás poderes en el Estado liberal.

Por lo que respecta a la primera tendencia, ha sido básicamente la historia crítica del derecho la que ha puesto de relieve la pervivencia de una concepción jurisdiccionalista del poder político en el primer tercio del siglo XIX y las consecuencias que esto tuvo en la elaboración de los distintos textos constitucionales (Cádiz, Apatzin-

\footnotetext{
${ }^{6}$ La múltiple reacción al formalismo ha originado diversas escuelas que la literatura sobre el tema tiende a agrupar en: la escuela científica, jurisprudencia de los intereses, jurisprudencia finalista, el movimiento del derecho libre, el realismo estadounidense o los Critical Legal Studies. Para una visión de estas tendencias en ámbito hispano, con atención al hispanoamericano, Perez LuÑo, 2007. Para una síntesis, Tiмm, 2010.

${ }^{7}$ Ibídem, p. 21. Entre otros véase Sisley, 2010, pp. 470-479; Ansolabehere, 2008, pp. 331-359; QuiÑonez Huizar, 2005, pp. 633-659; CÁRdenas Gutiérrez, 2009, pp. 1-23.
} 
gan, o la repercusión de ambos en la constitución federal ${ }^{8}$ ), así como en la reorganización de los territorios (y sus derechos) y los poderes, y en la definición de un modelo de justicia específico.

Estos análisis interpretan los procesos ocurridos a principios del siglo XIX en el contexto de significación de la cultura jurídica hispana "precontemporánea", reconstruida a partir de una lectura densa de la literatura ético-jurídica del Antiguo Régimen. Así, desde una suerte de antropología política muy crítica con el paradigma estatalista ${ }^{9}$, se recompone una comprensión preliberal del poder político, conceptualizado como iurisdictio; esto es, circunscrito a la potestad de decir el derecho ${ }^{10}$. De tal manera que el poder político sería un poder subsidiario del derecho, un instrumento de éste, limitado y sometido por él, cuya función fundamental es la de conservar el orden constituido.

Según estas interpretaciones, la comprensión de "lo jurídico" y de "lo político" en este momento estaría fuertemente condicionada por un imaginario dominado por una cosmovisión religiosa que reconoce un orden divino (natural e indisponible) que asigna a cada parte de la totalidad una posición y un destino. Este orden, que debe ser respetado, puede ser revelado, y lo es a través de la tradición textual (teológico jurídica) y de la tradición histórica de los diversos estados y corporaciones que conforman la vida social, objetivándose en una constitución tradicional que encarnaría los derechos propios de cada uno de ellos. Precisamente su capacidad para autoadministrarse hace que puedan entrar en conflicto, por lo que el poder político sería el encargado de, valiéndose de distintos dispositivos institucionales ideados a tal fin (procedimientos o mecanismos, prácticas o instrumentos), asegurar el orden, manteniendo "a cada uno en su derecho". En definitiva, el ejercicio del poder político consistiría "principalmente en la resolución de conflictos entre esferas de intereses diversas, atendiendo a los derechos y deberes constituidos o radicados en el orden jurídico"'11. Como ha explicado Carlos Garriga, se trata de un orden de derechos judicialmente garantizados que define un modelo judicial de gobierno que presuponía que el poder de juzgar y el de mandar, aunque distinguibles, eran inseparables ${ }^{12}$.

En el marco de esta cultura jurisdiccional y sus dispositivos institucionales, se cuestiona la consideración de "revolución" al proceso acontecido en ámbito hispano tras la crisis de 1808 y sus derivas novohispanas, ya que se incide prioritariamente en la pervivencia de la cultura jurisdiccional precedente desde varios aspectos: entre otros, la "inexistencia de un campo autónomo de lo político", que no estuviera supeditado al derecho ${ }^{13}$; la pervivencia de una comprensión historicista del poder político

\footnotetext{
${ }^{8}$ Con carácter general, sobre la interpretación de la constitución de Cádiz, Garriga - Lorente, 2007; Garriga, 2010, pp. 35-125; Lorente, 2010, pp. 293-384.

${ }^{9}$ Sobre la metodología e influencias de esta escuela, HesPanha, 2002, p. 26 y ss. También Garriga, 2004 y Grossi, 2006.

${ }^{10}$ Costa, 1969; Garriga - Lorente, 2007, p. 59.

${ }^{11}$ Garriga, 2007, p. 68.

12 Ibídem, p. 68. Sobre la preeminencia de la religión, el carácter tradicional, pluralista y probabilista del orden jurídico del Antiguo Régimen y su relación con el poder político, pp. 59-72. Sobre los distintos aspectos del Estado moderno europeo, Fioravanti (ed.), 2004.

${ }^{13}$ Annino, 2010, p. 14.
} 
(frente a una comprensión voluntarista, tal y como se expresó en la revolución francesa) ya que la "revolución hispana" no refutó las leyes antiguas sino que las adaptó a la nueva situación ${ }^{14}$, llegando incluso a adquirir una formulación constitucional "que ponía los viejos dispositivos institucionales que garantizaban los derechos corporativos al servicio de la "libertad de la nación", como la gran corporación formada por los españoles de ambos hemisferios" 15 . Sobre la reconstrucción de la cultura jurídica desde estos presupuestos, se ha puesto sobre la mesa la pervivencia de derechos corporativos territoriales y su influencia en la reorganización territorial tras 1808 , con especial atención al autonomismo (frente al Imperio y al interior del mismo, desde una perspectiva local y provincial), así como la relación entre las corporaciones indígenas y el derecho del Estado; el carácter jurisdiccional de la Constitución de Cádiz y sus consecuencias en los textos constitucionales mexicanos; la expresión constitucional y el desarrollo de un modelo de justicia que se ha denominado "justicia de jueces frente a la justicia de leyes" que hace hincapié en que se mantuvo la pluralidad de órdenes normativos, el arbitrio judicial y la casuística como dispositivos para ejercer la administración de justicia ${ }^{16}$.

Precisamente, la reflexión sobre la concepción del derecho y de la ley en el mundo moderno y sus implicaciones en el proceso de conformación de los Estados nacionales ha permitido conocer mejor la transformación del modelo de justicia que se produjo entre fines del XVIII y mediados del XIX. Así, los desarrollos del derecho natural moderno, el progresivo asentamiento del imperio de la ley, y con él del formalismo y el positivismo jurídicos y, en definitiva, de la estatización del derecho (absolutismo jurídico, en palabras de Paolo Grossi ${ }^{17}$ ) habrían coadyuvado a la transición de una justicia de casos, de equidades, de legos, basada en el arbitrio y en la pluralidad de fuentes, a una justicia de leyes, de especialistas en derecho, codificada, positiva y pretendidamente sistemática ${ }^{18}$.

Los estudios que atienden a la justicia como una de las expresiones del poder político definidas por los ideales liberales se plantean igualmente un amplio abanico temático que va desde la influencia de la escolástica en la conceptualización de la justicia en los textos constitucionales de algunos insurgentes relevantes o la recuperación del ius commune en textos doctrinales que abordaban el complejo problema de la integración de la ley en el siglo XIX. Asimismo, se ha mantenido el interés por los órganos judiciales de dimensión nacional más relevantes a lo largo del XIX, destacando sus diferencias en las repúblicas federal y central respectivamente, así como el proceso de conformación de la justicia en las distintas entidades federales; la per-

\footnotetext{
${ }^{14}$ Garriga, 2010, pp. 35-125.

15 Garriga, 2007, p. 72.

${ }^{16}$ La mayoría de estos aspectos se recogen en las distintas colaboraciones que componen ANNINO (ed), 2010. Especialmente, para el autonomismo, Portillo, 2010, pp. 125-190; RoJas, 2010, pp. 191-220; Lorente, 2010, pp. 293-383. También en Lorente (coord.), 2007; Annino, 2008; Portillo, 2006.

17 Grossi, 2003.

18 Sobre las implicaciones de estos aportes analíticos para una interpretación históricamente contextualizada del complejo proceso de imposición de la visión legalista del derecho en el caso mexicano, Del Arenal, 1999.
} 
vivencia de los fueros (militar y eclesiástico) y su repercusión política, o los distintos procesos de codificación, entre otros ${ }^{19}$.

Por su parte, los estudios sobre los "agentes de justicia" se han concentrado en torno a los abogados y los "juzgadores". Por lo que respecta a los abogados, las temáticas y perspectivas de trabajo han sido múltiples: el estudio de la diversificación y transformación de las instituciones que formaban y titulaban a los abogados, el mayor protagonismo que éstos fueron adquiriendo en la reconfiguración del Estado mexicano, especialmente ante la necesidad de que cada estado contara con especialistas del derecho, la transformación de su identidad corporativa (que pasó de aspirar a ocupar un lugar en la estructura organicista del Antiguo Régimen a intentar ser reconocida como un grupo de profesionale $\mathrm{s}^{20}$ ) o la estrecha relación entre la conformación del Estado asentado sobre los principios liberales y la formación de especialistas en leyes. Así, destaca la vinculación que se ha establecido entre la institucionalización del Estado y la formalización y regulación de los procesos académicos de formación de los abogados. La mayoría de estos trabajos muestran cómo las autoridades estatales intervinieron cada vez más en la legitimación de la función de los juristas (en detrimento de los intereses corporativos), acabando con la matriculación obligatoria en el Ilustre y Real Colegio de abogados para poder ejercer dicha función, definiendo los temarios de estudios o gestionando los procesos de titulación (tribunal superior de justicia o el gobernador). Sin embargo, y paradójicamente, esta "liberación" de la corporación y mayor estatalización de la profesión no implicó automáticamente la igualación de los abogados, puesto que se activaron nuevos mecanismos de desigualdad dentro de este cuerpo ${ }^{21}$.

El estudio de los juzgadores se ha emprendido desde la óptica de su proyección o aceptación social, tanto corporativa como individualmente, destacando aspectos como la imagen pública del juez atendiendo a valores como el "honor personal y la dignidad de la magistratura", en su doble faceta de posesión de cualidades personales específicas y expresión de las mismas en un espacio público. La mayoría de estos análisis coinciden en mostrar la imagen honorable del juez como un constructo social elaborado a partir tanto de su "honorabilidad ideal, virtuosa", como de su pericia y competencia atestiguada por el desempeño de su labor ${ }^{22}$.

Quizá una de las temáticas más sugerentes, por cómo se ha planteado, tiene que ver con la reflexión sobre quién debiera ser el juzgador en un contexto (liberal) en el que la justicia se administraba en nombre del pueblo soberano, asunto que ha sido tematizado prioritariamente en torno a la justificación del establecimiento de los jurados populares para determinados delitos. Se ha explicado cómo a pesar de su falta de

${ }^{19}$ Platas Pacheco, 2005, pp. 601-632; Ortiz Treviño, 2005, pp. 473-498; Morales Moreno, 2005, pp. 407-448, 2006, pp. 99-117 y 2009, pp. 321-349; Abreu y Abreu, 2005, pp. 3-21; Arnold, 2005, pp. 23-54; GonzÁlez Watty, 2005, pp. 207-233; Pérez Fonticoba, 2005, pp. 571-599; Adame Goddard, 2004; Sousa, 2005, pp. 715-742; Cruz Barney, 2004.

${ }^{20}$ Mayagoitia, 2009, pp. 199-241.

${ }^{21}$ Hernández Díaz, 2009, pp. 77-111; Mayagoitia, 2005, pp. 263-406; Téllez, 2009, pp. 241-273; Mayagoitia, 2002, pp. 339-474; Pérez Perdomo, 2003, pp. 545-600; Speckman Guerra, 2009, pp. 349-377.

22 CÁrdenas Gutiérrez, 2005, pp. 55-88. 
formación jurídica, la defensa del juicio por jurados se construía en consonancia con el principio de soberanía del pueblo (impartición de justicia por el pueblo soberano), el horizonte liberal de una mayor garantía de autonomía en el poder de juzgar frente al control del ejecutivo o legislativo e incluso frente a la corrupción, la publicidad del juicio como baluarte en la defensa de los derechos ante posibles abusos de autoridad, la confianza en que el juicio por pares aseguraría la igualdad jurídica, etc. Si su legitimación y puesta en práctica dependía de la definición de la articulación entre los poderes estatales y los atributos de la ciudadanía, la regulación de restricciones en la conformación de los jurados populares expresaba las distinciones y prejuicios sociales sobre determinados grupos sociales. El juicio por jurado correspondía al modelo de la justicia de los iguales y permitía la participación de particulares en el ámbito judicial ${ }^{23}$.

Por último, desde la historia de la justicia se han desarrollado iniciativas que tratan de ver el mundo jurídico en sentido amplio desde una perspectiva relacional y en pleno movimiento, en la que se cruzan la legislación existente, las conceptualizaciones de la justicia entre los grupos de profesionistas, especialmente los jueces o los intermediarios, y los múltiples imaginarios sociales sobre la justicia. Se trata de trabajos que, a partir del estudio de la puesta en práctica de los dispositivos judiciales, muestran a la cultura jurídica en acción, evidenciando cómo los ineludibles condicionamientos culturales dificultan la viabilidad de la uniformidad y la objetividad en la aplicación de la ley. Esta perspectiva está estrechamente vinculada a análisis elaborados desde la historia social, ya que muestra la diversidad de imaginarios, representaciones o prejuicios sobre la justicia, sus relaciones y sus consecuencias prácticas en un mismo contexto. Aunque no es el único ${ }^{24}$, quizá el trabajo paradigmático en este sentido sea el de Elisa Speckman, que ha tratado de rastrear la distancia entre la norma legal y la práctica judicial en la ciudad de México en el Porfiriato. Para ello ha estudiado desde la perspectiva de la historia de las ideas y de las mentalidades la legislación penal emitida entre 1872 y 1910 con el fin de recomponer la interpretación de la criminalidad, la administración de justicia y del castigo, las normas de conducta y el código de valores que reflejaba, así como su interacción con las ideas, preconcepciones o imaginaciones de otros sectores sociales, y en qué medida y de qué manera (voluntaria, involuntaria, consciente o inconscientemente) los jueces se apegaron o se alejaron de dicha legislación. Así la distancia entre el ideal liberal de justicia y su realización se habría expresado en la violencia de la independencia del poder judicial y en la aplicación de sentencias que no se sujetaban a derecho. Entre otros resultados, este trabajo aporta argumentos para la reflexión sobre la idea de que la codificación finiquita la posibilidad de interpretación de los jueces o cierta arbitrariedad judicial, cuestionando en última instancia la capacidad de la ley para prevenir, regular y/o aniquilar los espacios subjetivos en la administración de justicia; asimismo muestra la existencia de una considerable aceptación y confianza de distintos sectores sociales en el sistema judicial existente en el periodo, así como la presencia de concepciones

\footnotetext{
${ }^{23}$ Para más detalles, Speckman Guerra, 2005a, pp. 743-788; Padilla Arroyo, 2000, pp. 137-140.

${ }^{24}$ Narváez, 2005, pp. 449-473; LóPez GonZÁLez, 2006, pp. 1289-1351; Marino, 2006, pp. $1353-$ 1410; Speckman Guerra, 2002.
} 
alternativas a la liberal en los códigos y en las decisiones de los jueces, algunas propias del catolicismo del Antiguo Régimen y otras propias del positivismo.

Las temáticas y perspectivas de análisis hasta aquí apuntadas abordan la historia de la justicia atendiendo a la relevancia de las tradiciones culturales, de los imaginarios y las representaciones sociales en la conformación de la legalidad y de las instituciones vinculadas a la administración de justicia, así como en los momentos de aplicación de la misma por parte de los agentes estatales designados para ello.

\section{LA VISIÓN DE LA JUSTICIA DESDE LA HISTORIA SOCIAL}

Los trabajos emprendidos desde la historia social vinculan la interacción entre el Estado y la sociedad con la modernización, entendida como un proceso "cambiante, maleable y sensible a la acción" de los distintos sectores de la sociedad ${ }^{25}$. Asumiendo los presupuestos teóricos de un marxismo de los movimientos sociales reformulado, de la teoría de la subalternidad, especialmente de las aportaciones de Barrington Moore, y de la teoría de la resistencia (sobre todo, James C. Scott) tratan de analizar cuál fue la reacción de la sociedad civil -individual y colectivamente- en el proceso de implementación de un proyecto modernizador cuyo ideal era la consolidación de un Estado nación asentado sobre una concepción individualista de la sociedad y sobre la exclusiva lealtad de sus ciudadanos a la nación y al Estado. Para alcanzar tal horizonte resultaba imprescindible finiquitar las adscripciones corporativas y los derechos e identidades a ellas vinculados, así como asegurar el control y la corrección de aquellas conductas individuales (o colectivas) consideradas "desviadas" que pudieran poner en peligro los consensos implícitos en el pacto social o la autoridad derivada de ellos ${ }^{26}$.

Estos trabajos comparten la "mirada desde abajo"; esto es, desde los sectores sociales con menos poder (indígenas, artesanos, peones acapillados, negros, libertos, comunidades, pueblos y municipios) que fueron considerados como grupos sociales inferiores y amenazantes; desarrollan una conceptualización de la ley como un campo de negociación entre el Estado y la sociedad civil, y presentan la apelación a la justicia como una estrategia más en defensa de sus derechos. Ello permite reconfigurar la imagen que se tenía de los grupos subalternos como sujetos pasivos movilizados únicamente desde arriba, y se destaca su carácter activo en la implementación de varios mecanismos "para exigir sus demandas y plantear necesidades que, hasta cierto punto, debieron ser escuchadas" ${ }^{27}$. Dichas reacciones tuvieron además diferentes intensidades: el uso interesado e instrumental de las leyes y los procedimientos jurídicos para garantizar objetivos en cierta manera en conflicto con las pautas ideales del Estado liberal, la infracción (premeditada o no) de las normas sociolegales o la disidencia, en un amplio espectro que iría desde las pequeñas resistencias "cotidianas y simbólicas" como "el engaño, la haraganería, el incumplimiento pasivo, el hurto,

\footnotetext{
${ }^{25}$ BAUd - PARra, 2002, p. 248.

${ }^{26}$ Entre las principales influencias teóricas: Thompson, 1991; Moore, 1989; Scott, 2000.

27 Marino, 2006, pp. 1353-1354.
} 
las calumnias y chistes, el robo, el sabotaje o los incendios premeditados", hasta acciones colectivas en forma de revueltas ${ }^{28}$. Atendiendo a la diversa naturaleza de los actores sobre los que construyen su investigación, aquí resaltaremos dos líneas de trabajo que aglutinan, grosso modo, algunas de las principales aportaciones sobre estas temáticas: los versados sobre el ámbito rural, con especial desarrollo en las comunidades indígenas; los estudios que tratan sobre los delitos, entre los que destacan los de carácter leve en ámbitos urbanos. Es necesario apuntar además, la proliferación de investigaciones sobre el tema y las perspectivas desde las que se está desarrollando, el interés creciente por las cuestiones de género y su relación con la justicia. Todos estos estudios de caso recomponen de manera complementaria la heterogeneidad de los procesos sociales en la conformación nacional como una historia cargada de "acomodos, negociaciones, defensas y rebeliones" 29 .

Desde la perspectiva de la acción colectiva, compartiendo elementos analíticos propios de la historia agraria y con importantes desarrollos de la historia regional, puede identificarse un grupo de trabajos orientados prioritariamente al estudio de las comunidades campesinas e indígenas, las localidades menores, los pueblos o los municipios. Su interés se concentra en ver cómo se insertaban estos sujetos corporativos en una lógica estatal dirigida a finiquitar las identidades y los derechos colectivos de carácter consuetudinario para lo que toman en cuenta principalmente la segunda mitad del siglo XIX. En cuanto a las temáticas que abordan, destacan especialmente la aplicación de la ley de desamortización, conocida como Ley Lerdo, y sus consecuencias, y la labor realizada por la Junta Protectora de Clases Menesterosas, que acogió, aunque no sólo, las heterogéneas demandas y peticiones de las comunidades indígenas: la mayoría de ellas quejas y abusos de malos tratos o reclamaciones relacionadas con la propiedad y el usufructo de tierras y aguas.

La problemática central de la que parten estos estudios es la aprobación de la conocida como Ley Lerdo, que implicaba la abolición de la personalidad jurídica de los pueblos en materia de propiedad y ordenaba la desamortización de sus tierras, con excepción de los ejidos, y las repercusiones de su aplicación hasta el momento revolucionario. Se han ofrecido múltiples puntos de vista que han permitido constatar cómo esta ley pretendía desarticular las identidades y solidaridades corporativas, consideradas antiguas, y no otro tipo de asociacionismo que interesaba más, por distintos motivos, al proyecto modernizador de construcción estatal. Así, se ha puesto de relieve que la desamortización quiso atacar no solo la propiedad de la Iglesia sino también la de las comunidades campesinas ${ }^{30}$. Estos mismos estudios muestran, sin embargo, que los pueblos y las comunidades indígenas consiguieron que el Estado les reconociera, aunque fuera de manera indirecta, su personalidad jurídica (apelando, por ejemplo, al recurso de amparo $\left.{ }^{31}\right)$; que dichos colectivos lograron preservar el carácter comunitario de sus propiedades (principalmente tierras, pero también aguas

\footnotetext{
${ }^{28}$ Escobar Ohmstede - FAlcón, 2002, p.12.

${ }^{29}$ Ibidem, p. 12.

30 Frente a la extendida idea de que la Reforma solo quiso atacar a la propiedad amortizada en manos de la iglesia. MARINO, 2005a, p. 239.

${ }^{31}$ LiRA, 2009, pp. 111-171; MARINO, 2005a, p. 243.
} 
o sal) y que, en definitiva, fueron capaces de adaptar elementos procedentes del derecho consuetudinario a las nuevas figuras jurídicas liberales.

Los numerosos estudios que atienden a las diversas regiones del país muestran cómo el recurso a la justicia por parte de las comunidades fue una práctica habitual para reclamar y defender sus derechos frente a lo que pudieron considerar amenazas, usurpaciones o violencias ${ }^{32}$. Para el caso del centro de México, destacan especialmente los trabajos de Daniela Marino, que recompone, atendiendo a distintas expresiones de esta conflictividad, el período que va desde la Reforma hasta el fin del Porfiriato, mostrando la vía jurídica y judicial de la negociación de las comunidades indígenas con el Estado. A través de sus análisis se han podido conocer mejor las concepciones de justicia construidas por las culturas campesinas de esta región y las maneras en las que éstas consiguieron insertar en la legislación liberal el reconocimiento de sus derechos (basados en la costumbre) sobre los recursos naturales y sobre la administración del territorio ${ }^{33}$. Así, sus reflexiones no sólo confirman la tesis de que los pueblos tenían un conocimiento detallado y actualizado de la legislación vigente que afectaba a sus intereses, que sabían cuáles eran las ocasiones en las que podían apelar para defender sus derechos y que entendían el funcionamiento del aparato judicial ${ }^{34}$, sino también y sobre todo, que tenían un gran dominio de la puesta en escena en sus demandas, muy especialmente de las estrategias discursivas más rentables para ganarse el favor de la autoridad (algo especialmente contrastado para el Segundo Imperio). Según esta autora, sabían que "exhibir su pobreza, su ignorancia, su debilidad frente a la codicia de los hacendados y la corrupción de las autoridades, [o] implorar por el "porvenir de nuestros hijos" y por la "subsistencia y el bienestar" podían resultar muy efectivos; apelaban a instrumentos jurídicos coloniales (mercedes, reales cédulas, Recopilación de Indias $)^{35}$ o combinaban argumentos propios del universo referencial liberal (presentándose como patriotas, ciudadanos ejemplares, cumplidores con el pago de impuestos y el servicio al ejército liberal) y del Antiguo Régimen (apareciendo como súbditos que debían ser socorridos, amparados por la misericordia y compasión de un monarca paternalista y protector) en función de las distintas coyunturas nacionales ${ }^{36}$.

Procesos y estrategias de adaptación, respuesta y/o reconocimiento que se dieron en todas las comunidades y que tuvieron consecuencias tanto en el interior de las mismas como en su relación con propiedades privadas colindantes ${ }^{37}$. Así, por lo que respecta a la tenencia y uso de las tierras, Antonio Escobar Ohmstede ha detallado la variedad en las reacciones: "hubo pueblos que de manera casi inmediata a la ley

${ }^{32}$ Para el caso del Estado de México, en época Juarista los trabajos de María del Carmen Salinas y Diana Birrichaga muestran muy bien está dinámica. Salinas Sandoval - Birrichiga Gardida, 2007, pp. 207-253.

33 Marino, 2006, pp. 1353-1354. para saber más acerca de su participación en procesos conciliatorios, MARINO, 2005c.

34 Marino, 2006, p. 1391.

35 Ibidem, p. 1394.

${ }^{36}$ Ibidem, pp. 1400-1401; Marino, 2005b, pp. 237-264. Sobre esto mismo, López GonZÁlez, 2006, pp. 1289-1351.

${ }^{37}$ En este mismo sentido, Salinas Sandoval - Birrichiga Gardida, 2007, p. 239. 
de 1856 solicitaron el deslinde e individualización de los terrenos comunales; otros realizaron ventas ficticias entre sus pobladores; unos más conservaron de manera comunal gran parte de sus tierras hasta después de 1870 o 1875 ; y otros se conformaron en sociedades agrarias o condueñazgos" ${ }^{\prime 3}$. Por ejemplo, en la Mixteca, según ha mostrado Edgar Mendoza, algunos ayuntamientos consiguieron administrar sus tierras y determinados bienes comunales gracias a su capacidad para combinar sus tradiciones comunitarias con las leyes liberales municipales ${ }^{39}$. También hubo casos, como en Oaxaca, Chiapas, las Huastecas o los rarámuri de Chihuahua, en donde se crearon condueñazgos o estructuras propietarias similares que garantizaban el uso comunal de las tierras ${ }^{40}$.

Estas dinámicas sobre la personalidad jurídica y el acceso a los recursos naturales también afectaron a determinados aspectos referidos a la identidad cultural de las comunidades $^{41}$, así como a la configuración administrativa y territorial del Estado ${ }^{42}$. El Segundo Imperio, debido a su carácter dual entre un paternalismo propio de la monarquía colonial y un socialismo utópico ${ }^{43}$, ha constituido un ámbito de indagación sumamente interesante para observar las inflexiones y tonos empleados en las demandas de los colectivos ante el Estado. Junto con las aportaciones sobre los imaginarios y sus articulaciones, los trabajos sobre este período han destacado, además, la función institucional de la Junta Protectora de Clases Menesterosas que "ayudó a contener la violencia, medió entre las partes en disputa y canalizó los requerimientos de los de abajo" "44, constituyendo una instancia fundamental en la articulación de la interacción entre los grupos sociales más desfavorecidos y la autoridad nacional.

En su conjunto, estos trabajos han matizado algunos de los presupuestos historiográficos tradicionales que afectaban a la consideración de los indígenas, del Estado y de la relación entre ambos. Por un lado, han reconfigurado una imagen más comedida y verosímil de las comunidades indígenas que dejan de aparecer como fuerzas tradicionalistas, subversivas y/o aisladas del proceso de conformación estatal, al mostrar cómo no solo no propusieron un "retorno absoluto a antiguas prácticas y formas de vida centenarias", sino que demostraron una vigorosa capacidad de adaptación a la realidad cambiante con el fin de garantizar su autonomía y sus recursos ${ }^{45}$. Aparecen como sujetos activos que supieron defender sus derechos corporativos, por lo que

\footnotetext{
${ }^{38}$ Escobar Ohmstede, 2007, p. 28.

39 El logro de los ayuntamientos mixtecos se debió a que tenían tareas comunales que no estaban reguladas por la ley, conservando sus recursos naturales, supervisando asuntos religiosos y organizando fiestas patronales. MENDOZa GarCía, 2005, pp. 209-236 y 2007, pp. 151-170;

40 Camacho Pichardo, 2005, pp. 265-285; Ortiz Yam, 2005, pp. 285-306, Gutiérrez Grageda, 2005, pp. 307-329; LOPES, 2005, pp. 329-351.

${ }^{41}$ Brian Hammett, por ejemplo, aborda la resistencia en el mantenimiento de la identidad étnica de estas comunidades en el caso de Oaxaca. Hammetт, 2002, pp. 189-205.

${ }^{42}$ El estudio de Chassen sobre los juchitecos nos muestra cómo el conflicto por el control de la sal por parte del gobierno federal, estatal y los indígenas "llevó en ocasiones a planteamientos de creación de entidades políticas, en donde el dirigente funcionó como una especie de intermediario cultural y defensor del movimiento multiétnico". CHASSEN, 2007, pp. 37-69; 23.

${ }^{43}$ FALCÓN, 2002, p. 128.

${ }^{44}$ Ibídem, p. 128.

${ }^{45}$ Ibídem, p. 134. Según Falcón, eran "expertos en la negociación en corto".
} 
respecta especialmente a los recursos naturales, que hicieron uso de las instituciones mediadoras y los procedimientos jurídicos estatales que pudieron servirles en la defensa de los mismos, que recurrieron a la mediación del Estado en sus conflictos con otras comunidades, utilizando en todos estos procesos una retórica diversa y heterogénea y apelando a derechos antiguos y a derechos liberales en función de la necesidad para legitimar sus demandas. Por otro lado, se ha complejizado la visión monolítica sobre el Estado como autoridad que impone su dominación a través de la ley y aparece ahora como una institución con capacidad de transformación, de diálogo (en distintas intensidades) con la sociedad, de incorporación de sus reclamos y, en ocasiones, sustentado gracias a la consideración de dichas demandas. Por último, se matizan las tradicionales miradas dialécticas y simplificadoras de la relación entre los sectores subalternos y el Estado. Ésta ya no se explica desde la perspectiva de imposición del proyecto modernizador (y sus secuelas homogeneizadoras) de las elites sobre las comunidades indígenas en clave de sometimiento absoluto o resistencia total, sino que se analiza considerándola como un complejo proceso de negociación que implicó a múltiples actores (sociales, institucionales, jurídicos, etc.) y que fue adquiriendo texturas diferentes en cada coyuntura.

La "problemática rural" que comparten todos estos análisis ha sido puesta en relación con dos contextos diferentes: mientras para los estudiosos interesados en analizar las dificultades y contradicciones de la integración de lo corporativo en el nuevo escenario liberal las comunidades indígenas constituyen un objeto de estudio en sí mismas, para otros investigadores esta problemática forma parte de un campo de estudio de mayor dimensión: el de los pobres y marginados. Sobre este punto de vista ha insistido Romana Falcón en sus trabajos, para quien los campesinos son "los pobres del campo" que comparten condición, carácter y reacciones con los pobres de la ciudad.

Aparece así una línea de investigaciones que, interesadas especialmente en las reflexiones acerca de los procesos de modernización y urbanización y en los cambios sociales derivados de ellos, se concentran en el estudio de los sectores populares en contextos citadinos. Todas ellas coinciden en establecer una relación directa entre miseria y conducta delictiva, así como en reconocer una tendencia a la consideración de "delito" de comportamientos y prácticas populares de socialización en espacios públicos que eran vistos con miedo, desconfianza y horror por parte de los grupos hegemónicos. Se percibe la historia cotidiana de estos grupos como resistencias o disidencias frente a los sucesivos esfuerzos por moralizar y controlar sus conductas, concretamente, por regular su ocio, sus hábitos y comportamientos públicos, sus prácticas de socialización y diversión, en un contexto de producción capitalista que tiende a primar el valor del trabajo. Todos ellos comparten la consideración de que las figuras del "marginal", el "disidente" y el "criminal" ${ }^{46}$ fueron en gran medida resultado de un proceso de construcción social que tendía a clarificar las distinciones sociales y que se expresaría

${ }^{46}$ Felipe Castro matiza que mientras el delito ofende "los sentimientos colectivos, es decir, la totalidad de creencias y sentimientos comunes" en una sociedad, la disidencia supone un cuestionamiento implícito o explícito de la utilidad o legitimidad de las normas de dicha sociedad y provoca, independientemente de si es exitosa o no, transformaciones en las instituciones, las leyes, las ideas y costumbres. CASTRO, 2003, pp. 7-17. 
en la progresiva transformación del enjuiciamiento moral negativo de sus comportamientos (como deshonestos) a una criminalización de los mismos, que se manifestó no sólo a través de representaciones o de construcción de imaginarios, sino también en términos jurídicos y judiciales.

Temáticamente estas propuestas podrían concentrarse en dos polos: por un lado, en la legislación sobre vagos, mendigos y delitos leves en general; por otro, en la construcción cultural del crimen, lo que implicó la elaboración e instrumentalización de determinadas imágenes sobre el delito y el delincuente, así como a expresiones institucionales relacionadas con él (legislación penal y definición de sistemas de corrección y castigo). La ciudad de México ha constituido uno de los principales escenarios de investigación sobre estas temáticas.

La atención prestada a los delitos leves en la ciudad de México ha permitido reconstruir la estrecha relación entre la construcción social del honor y la decencia como valores morales que se adquirían básicamente por una dedicación regular al trabajo, y el control del ocio y el disciplinamiento de la presencia individual y colectiva en los espacios públicos como estrategias de actuación para asegurar el orden en las urbes. Los trabajos dedicados a estas temáticas muestran cómo la posesión de estos atributos morales dependía especialmente del reconocimiento de los otros, por lo que la condición de honrado y decente se dirimía en la vecindad, y a partir de ésta se decidía, entre otros aspectos, el acceso a la ciudadanía. En este contexto, Vanesa Teitelbaum muestra cómo si la precariedad material era causante en gran medida de los delitos leves (hurtos o el recurso a prácticas de empeño no reguladas) también permitía negociar los castigos y represalias de los mismos, especialmente entre los artesanos. A partir del examen de los argumentos que emplearon los sectores populares en la sustanciación de los sumarios elaborados por los alcaldes de cuartel y sus ayudantes a principios de 1850, destaca la apelación al honor como elemento de respetabilidad e inocencia. Atendiendo al delito de vagancia, Alejandra Araya, por su parte, contextualiza la creación del Tribunal de Vagos de México (1828-1836) y la vigencia de ciertas prácticas de exclusión social en el momento de definición de quiénes debían ser ciudadanos y quiénes no. Así, bajo una conceptualización voluntarista de la tendencia a delinquir, según la cual se presuponía que el sujeto que delinquía lo hacía por decisión propia (a diferencia del positivismo que consideraba que el sujeto estaba predeterminado a ello), el no tener una ocupación laboral reconocible se consideraba expresión de vida deshonesta y por tanto inhabilitaba para disfrutar de los beneficios de la ciudadanía. La creación del tribunal resultó, en este sentido, un instrumento fundamental de los artesanos de la ciudad para distinguirse frente a los sectores más populares sin ocupación permanente. Esta discriminación entre los insertos en el sistema y los marginales y peligrosos en el ámbito urbano resultaba especialmente relevante en situaciones de extrema emergencia, como fue el caso de la ocupación norteamericana de la capital en el momento de la guerra con EE.UU. y continuó en el periodo del Porfiriato. De hecho, no se trató de una problemática exclusiva de la ciudad de México, sino que también se dio en otras urbes del país ${ }^{47}$.

47 Teitelbaum, 2006, pp. 1221-1287; Araya Espinosa, 2005, pp. 45-73; Cosamalón, 2005, pp. 99138; Barbosa Cruz, 2005, pp. 165-186; Pérez Mungia, 2005, pp. 73-98. 
Los trabajos dedicados a la segunda mitad de siglo tienden a relacionar la aplicación del código penal aprobado en 1871, la intervención de los criminólogos y la conformación de representaciones sobre los criminales. Todo ello desarrolló un ideario, una imaginación sobre la delincuencia, la inseguridad y la peligrosidad que pudieron resultar estrategias valiosas en el disciplinamiento y control social. En este marco, los estudios de Pablo Piccato ponen en evidencia la naturaleza construida de las categorías de delito y de crimen, su utilidad para clasificar a la población citadina, y las repercusiones imprevistas de las medidas represivas adoptadas sobre ellas. Consecuencias que afectarían a la propia consideración de los criminales como grupo social (como el caso de los rateros) y a la percepción social de la inseguridad y la violencia en las ciudades ${ }^{48}$. Las explicaciones deterministas que afectaban a grupos marginales específicos y sus interacciones en la conformación de un ideario sobre la tendencia natural y/o social de éstos hacia el crimen y la delincuencia han dado lugar a interesantes estudios sobre sectores como el indígena, los menores o las mujeres ${ }^{49}$. Estos trabajos se han completado con análisis acerca de los distintos procedimientos orientados a contener o castigar la transgresión y el delito, entre los que destacan los estudios sobre los sistemas carcelarios ${ }^{50}$.

\section{CONSIDERACIONES FINALES}

La historia judicial se ha convertido en las últimas décadas en un campo atractivo para historiadores, juristas, antropólogos o sociólogos. Esta convivencia, unida a la propia autorreflexión que se ha producido en cada una de estas disciplinas, está generando espacios de intercambio que contribuyen a flexibilizar las comprensiones rígidas y reduccionistas acerca de la interacción entre la sociedad, el derecho y el Estado. El reconocimiento de la capacidad de actuación de los distintos actores sociales en la formulación y aplicación de la ley, la consideración contingente de ésta y la reevaluación de la conceptualización monolítica del Estado como autoridad impositiva son algunos de los puntos de inflexión más interesantes aportados por los trabajos aquí esbozados. Todos ellos insisten, desde una especial atención a las prácticas y a los actores, en la dimensión cultural y social de los procesos de normativización y en sus profundas implicaciones políticas.

Las fuentes judiciales constituyen un material muy fértil para el estudio de la historia de México a lo largo de su proceso de conformación nacional, no sólo para la historia del derecho, sino también para la historia social y política. Así, por ejemplo, han contribuido a reabrir el interés sobre determinados actores políticos y su función jurisdiccional, como es el caso de los alcaldes, y las repercusiones que tuvo en la recomposición de las jerarquías territoriales y de poderes el reconocimiento por parte

${ }^{48}$ Piccato, 2001, pp. 233-275.

49 Speckman Guerra, 2005b, pp.225-253; Urías Horcasitas, 2000; Núñez Becerra, 2002; SPeCKMAN Guerra, 2003.

${ }^{50}$ Padilla, 2001 y 2004, pp. 247-276. 
del Estado de su potestad para intervenir en la resolución de conflictos que afectaban a la vida cotidiana del país recién emancipado.

\section{REFERENCIAS BIBLIOGRÁFICAS}

AA.VV.

2005 Historia de la Justicia en México. México. Suprema Corte de la Justicia de la Nación. 2 tomos.

Abreu y Abreu, Juan Carlos

2005 "La justicia constitucional a dos fuegos: federalistas contra centralistas". En AA.VV., tomo I, pp. 3-21.

Adame Goddard, Jorge

2004 El matrimonio civil en México (1859-2000). México. UNAM-IIJ.

Agostini, Claudia y Speckman Guerra, Elisa (eds.)

2005 De normas y transgresiones. Enfermedad y crimen en América Latina (1850-1950). México. UNAM.

Aguirre, Carlos y Buffington, Robert (eds.)

2000 Reconstructing Criminality in Latin America. Wilmington. Scholarly Resources.

AnNino, Antonio

2008 "Imperio, constitución y diversidad en la América hispana". Historia mexicana. México. vol. LVIII: 1, pp. 179-227.

2010 "Introducción. La política en los tiempos de la independencia". En AnNino (coord.), pp. 11-35.

AnNino, Antonio (coord.)

2010 La revolución novohispana, 1808-1821. México. CIDE - FCE CONACULTA - INEHRM - Fundación cultural de la ciudad de México.

Ansolabehere, Karina

2008 "Legalistas, legalistas moderados y garantistas moderados: ideología legal de maestros, jueces, abogados, ministros públicos y diputados". Revista Mexicana de Sociología. México. vol. 70: 2, pp. 331-359.

Araya Espinosa, Alejandra

2005 "De los límites de la modernidad a la subversión de la obscenidad: vagos, mendigos y populacho en México, 1821-1871”. En FalCón (coord.), pp. 45-73.

ARNOLD, Linda

2005 "Virtual Legality; Militar Justice and Fuero Militar, 1821-1832". En AA.VV., tomo I, pp. 23-54 
BANAKAR, Reza

2005 "Law through sociology's Looking Glass; Conflict and Competition in Sociological Studies of Law". En DenNIS - Kalekin-Fishman (eds.), pp. 58-73.

Barbosa Cruz, Mario

2005 "El ocio prohibido. Control "moral" y resistencia cultural en la ciudad de México a finales del Porfiriato". En FALCón (coord.), pp. 165-186.

Baud, Michiel y Parra, Alma

2002 "Respuestas, resistencias y acomodos a los procesos modernizadores en América Latina. Viejos problemas, nuevas perspectivas. Conclusiones generales". En Escobar OHMStede - BuvÉ (coords.), pp. 245-250.

CAmacho Pichardo, Gloria

2005 "Resistencias cotidianas ante la intervención estatal o federal: dos motines en torno al manejo de los recursos hidráulicos en el Estado de México, 1870-1900”. En FALCón (coord.), pp. 265-285.

CÁrdenAS GutiérRez, Salvador

2009 "Cultura jurídica". En Del Arenal - Speckman Guerra (coords.), pp. 1-22.

2005 "La imagen pública de los jueces mexicanos en el siglo XIX: una aproximación desde la arqueología judicial”. En AA.VV., tomo II, pp. 55-88.

CAstro Gutiérrez, Felipe

2003 "La introducción de los disidentes en la historia de México". En Castro, Felipe - Terrazas, Marcela. Disidencia y disidentes en la historia de México. México. UNAM, pp. 7-17.

Chassen, Francis R.

2007 “Una derrota juarista? Benito Juárez vs. los juchitecos”. En Escobar OHMSTEDe (coord.), pp. 37-68.

Cosamalón Aguilar, Jesús

2005 "Léperos y yanquis: el control social en la ciudad de México durante la ocupación norteamericana, 1847-1848”. En FALCón (coord.), pp. 99-138.

Costa, Pietro

1969 "Iurisdictio". Semantica del potere politico nella pubblicistica medievale. Milano. Giuffré.

CotTerRell, Roger

2008 Living Law: Studies in Legal and Social Theory. Aldershot. Ashgate.

CRUz BARNeY, Óscar

2004 La codificación en México: 1821-1917. México. UNAM.

Deflem, Mathiew

2008 Sociology of Law: Classical and Contemporary Perspectives. Cambridge. Cambridge University Press. 
Del Arenal, Jaime

1999 "El discurso en torno a la ley: el agotamiento de lo privado como fuente del derecho en el México del siglo XIX". En Connaughton, Brian Illades, Carlos - Pérez Toledo, Sonia (coords.). Construcción de la legitimidad política en México. México. El Colegio de Michoacán Universidad Autónoma Metropolitana - Universidad Autónoma de México - El Colegio de México, pp. 303-323.

2006a "La escuela mexicana de historiadores del derecho". Anuario Mexicano de Historia del Derecho. México. n 18, pp. 57-76.

2006b "De Altamira a Grossi: presencia de historiadores extranjeros del derecho en México". Historia Mexicana. México. vol. 55:4, pp. 1467-1495.

Del Arenal, Jaime y Speckman Guerra, Elisa (coords.)

2009 El mundo del derecho. Aproximaciones a la cultura jurídica novohispana y mexicana (siglos XIX y XX). México. IIHUNAM - Porrúa.

Dennis, Ann y Kalekin-Fishman, Devorah (eds.)

2005 The New ISA Handbook in contemporary international Sociology: Conflict, Competition and Cooperation. London. Sage.

Escobar OHMSTEDE, Antonio

2007 "Introducción. La "modernización" de México a través del liberalismo. Los pueblos indios durante el juarismo". En Escobar OHMStede (coord.), pp. 11-35.

Escobar Ohmstede, Antonio (coord.)

2007 Los pueblos indios en los tiempos de Benito Juárez. México. Universidad Autónoma Metropolitana.

Escobar Ohmstede, Antonio y Buvé, Raymond (comps.)

2002 Pueblos, comunidades y municipios frente a los proyectos modernizadores en América Latina. San Luis Potosí. El Colegio de San Luis.

Escobar Ohmstede, Antonio y Falcón, Romana

2002 Los ejes de la disputa. Movimientos sociales y actores colectivos en América Latina, siglo XIX. Madrid. AHILA - Iberoamericana - Vervuert.

FALCón, Romana

2002 "Subterfugios y deferencias. Indígenas, pueblos y campesinos ante el segundo imperio". En Escobar OHMSTEDE - BuvÉ (comps.), pp. 125-145

FALCón, Romana (coord.)

2005 Culturas de pobreza y resistencia. Estudios de marginados, proscritos y descontentos. México, 1804-1910. México. El Colegio de México Universidad Autónoma de Querétaro.

FioraVANTI, Mauricio (ed.)

2004 El estado moderno en Europa. Madrid. Trotta. 
GarRIGA, Carlos

2004 "Presentación". Istor. Revista de historia internacional. México. vol. 16.

2010 "Orden jurídico e independencia política: Nueva España, 1808 - México, 1821”. En AnNino (coord.), pp. 35-125.

Garriga, Carlos y Lorente, Marta

2007 Cádiz, 1812. La constitución jurisdiccional. Madrid. Centro de Estudios Políticos y Constitucionales.

GonZÁlez Watty, Andrés

2005 "Justicia mercantil y prácticas procesales durante el porfiriato". En AA.VV., tomo I, pp. 207-233.

Grossi, Paolo

2003 Mitología jurídica de la modernidad. Madrid. Trotta.

2006 La primera lección de derecho. Madrid. Marcial Pons.

GutiéRrez Grageda, Blanca Estela

2005 "Las lágrimas de la Magdalena. Agravios rurales y resistencia campesina en Querétaro al finalizar el siglo XIX”. En FALCón (coord.), pp. 307-329.

Hall, John R.; GrindstafF, Laura y Lo, Ming-Cheng (eds.)

2010 Handbook of Cultural Sociology. London and New York. Routledge.

HAMmetт, Brian

2002 "Los pueblos indios y la defensa de la comunidad en el México independiente, 1824-1884: El caso de Oaxaca". En Escobar Ohmstede

- BuvÉ (comps.), pp. 189-205.

Helman, Mark

1987 A Guide to Critical Legal Studies. Cambrigde. Harvard University Press.

HERNÁNDEZ DíAZ, Jaime

2009 "La formación de una nueva tradición jurídica en Michoacán: 18251844”. En Del Arenal- Speckman Guerra (coords.), pp. 77-111.

Hespanha, Antonio Manuel

2002 Cultura jurídica europea. Madrid. Tecnos.

Hutchinton, Alan C. (ed.)

1989 Critical Legal Studies. New Jersey. Rowman \& Littlefield Publishers, inc.

LIRA, Andrés

2009 "Los derechos del hombre, las personas morales y el juicio de amparon en los albores del siglo XX". En Del Arenal - Speckman Guerra (coords.), pp. 111-171.

LOPES, María Aparecida de S.

2005 "Crisis económica y desorden social en Chihuahua en vísperas de la revolución”. En FALCón (coord.), pp. 329-351. 
LÓPEZ GoNZÁLEz, Georgina

2006 "Cultura jurídica e imaginario monárquico: las peticiones de indulto durante el Segundo Imperio Mexicano". Historia Mexicana. México. vol. LV: 4, pp. 1289-1351.

LORENTE, Marta

2010 "Esencia y valor del constitucionalismo gaditano (Nueva España, 18081821)". En AnNino (coord.), pp. 293-384.

LORENTE, Marta (coord.)

2007 De la justicia de jueces a la justicia de leyes: hacia la España de 1870. Madrid. Consejo General del Poder Judicial.

MARINo, Daniela

2005a "Buscando su lugar en el mundo del derecho: actores colectivos, reforma y jurisprudencia". En AA.VV., tomo I, pp. 235-262.

2005b "La modernidad a juicio. Pleitos por la tierra y la identidad comunal en el estado de México, 1856-1910". En FALCón (comp.), pp. 237-264.

2005c "El juzgado conciliador en la transición jurídica. Huixquilucan (estado de México), siglo XIX". En Agostini - Speckman Guerra (eds.), pp. 195-225.

2006 "Ahora que Dios nos ha dado padre [...]. El segundo imperio y la cultura jurídico-política campesina en el centro de México". Historia Mexicana. México. nº. 220. vol. LV: 4, pp.1353-1410.

Mayagoitia, Alejandro

2002 "Las listas de matriculados impresas por el ilustre y real colegio de abogados de México". Ars Iuris. México. no. 27, pp. 339-474.

2005 "Los abogados y el Estado mexicano: desde la independencia hasta las grandes codificaciones". En AA.VV., tomo I, pp. 263-406.

2009 "Un cuerpo en busca de su lugar; la fiesta de Guadalupe del Ilustre y Real Colegio de Abogados de México (1760-1821)". En Del Arenal -SPeCKMAN Guerra (coords.), pp. 199-241.

Mendoza garcía, Edgar

2005 "Distrito político y desamortización: resistencia y reparto de la propiedad comunal en los pueblos de Cuicatlán y Coixtlahuacam, 1856-1900”. En FALCón (coord.), pp.- 209-235.

2007 "Organización y funcionamiento del gobierno local: los municipios de los distritos políticos de Teposcolula y Coixtlahuaca, 1857-1900". En Escobar OHMSTEDe (coord.), pp. 151-170.

Mijangos y González, Pablo

2011 El nuevo pasado jurídico mexicano. Madrid. Universidad Carlos III.

Moore, Barrington

1989 La injusticia: las bases sociales de la obediencia y la rebelión. México. UNAM. 
Morales Moreno, Humberto

2005 "Los órganos jurisdiccionales del poder judicial en los orígenes del Estado moderno en México (Federalismo, centralismo y liberalismo en su evolución histórica: 1824-1857)". En AA.VV., tomo I pp. 407-448.

2006 "El sexto circuito judicial del Estado de Puebla, 1826-1997". Anuario de Historia del Derecho Mexicano. México. no 18, pp. 99-117.

2009 "La práctica jurídica en el poder judicial poblano (1800-1831). (Aproximación histórica al Derecho de transición en el México de la primera mitad del siglo XIX). En Del Arenal - Speckman Guerra (coords.), pp. 321-349.

NARVÁEZ, José Ramón

2005 "Seducidas y robadas. Apuntes judiciales y extrajudiciales sobre el rapto en el siglo XIX". En AA.VV., tomo I, pp. 449-473.

NúÑEZ BECERRA, Fernanda

2002 La prostitución y la represión en la ciudad de México (siglo XIX). México. Gedisa.

Ortiz Treviño, Rigoberto Gerardo

2005 "Problemas de integración de la ley en el siglo XIX". En AA.VV., tomo I, pp. 473-498.

ORTIZ YAM, Inés

2005 "El descontento en los pueblos yucatecos a finales del siglo XIX. Una aproximación a la percepción de los milperos durante el proceso privatizador". En FALCÓN (coord.), pp. 285-306.

Padilla Arroyo, Antonio

2000 "Los jurados populares en la administración de justicia en México en el siglo XIX”. Secuencia. México. nº 47, pp. 137-165.

2001 De Belem a Lecumberri. Pensamiento social y penal en el México decimonónico. México. AGN.

2004 "Control, disidencia y cárcel política en el Porfiriato". Convergencia. México. n 36 , pp. 247-276.

Palacio, Juan Manuel y Candioti, Magdalena (comp.)

2007 Justicia, politica y derechos en América Latina. Buenos Aires. Prometeo Libros.

Perdomo Pérez, Alejandro

2003 "Los abogados americanos de la monarquía española". Anuario de Historia del Derecho Mexicano. México. no 15, pp. 545-600.

Pérez Fonticoba, Antonio

2005 "El ideario familiar en la legislación decimonónica mexicana". En AA.VV., tomo II, pp. 571-599. 
PÉREZ LuÑo, Antonio Enrique

2007 Trayectorias contemporáneas de la filosofía y la teoría del derecho. Madrid. Tebar.

Pérez Lledó, Juan A.

1996 El movimiento Critical Legal Studies. Madrid. Tecnos.

Pérez Munguía, J. Patricia

2005 "Los vagos y las leyes de vagancia en Querétaro. Continuidades y rupturas entre la colonia y el siglo XIX”. En FALCón (coord.), pp. 73-98.

Piccato, Pablo

2001 "Cuidado con los rateros: The Making of Criminals in Modern Mexico City”. En Salvatore - Aguirre - Gilbert (eds.), pp.233-272.

Platas Pacheco, María del Carmen

2005 "La noción de justicia en los Sentimientos de la nación de José Maria Morelos y Pavón”. En AA.VV., tomo. II, pp. 601-632.

Portillo Valdés, José María

2006 Autonomía e independencia en la crisis de la monarquía hispánica. Madrid. Fundación Carolina. Centro de Estudios Hispánicos e Iberoamericanos - Marcial Pons.

2010 "Monarquía, imperio y nación: experiencias políticas en el Atlántico hispano en el momento de la crisis hispánica". En AnNINo (coord.), pp. 125-190.

QuiÑonez HuIZAR, Francisco Rubén

2005 "Elementos para el análisis de la cultura jurídica en México. La evolución del concepto "cultura" y su relación con el sistema jurídico". En AA.VV., tomo II, pp. 633-659.

RoJAs, Rafael

2010 "Traducciones del autonomismo gaditano". En AnNino (coord.), pp. 191-220.

Salinas Sandoval, Carmen y BirRichiga Gardida, Diana

2007 "Conflicto y aceptación ante liberalismo. Los pueblos del Estado de México". En Escobar Ohmstede (coord.), pp. 207-253.

Salvatore, Ricardo; Aguirre, Carlos y Gilbert, Joseph (eds.)

2001 Crime and Punishment in Latin America. London. Duke University Press.

Scotт, James C.

2000 Los dominados y el arte de la Resistencia. Discursos ocultos. México. ERA.

Sisley, Susan S.

2010 "Legal Culture and Cultures of Legality". En HaLL - GrindSTAFF - Lo (eds.), pp. 470-479. 
Sousa Bravo, Alejandro

2005 "Equidad en la justicia: algunas consideraciones sobre el segundo imperio". En AA.VV., tomo II, pp. 715-742.

SPECKMAN Guerra, Elisa

2002 Crimen y castigo. Legislación penal, interpretaciones de la criminalidad y administración de justicia (Ciudad de México, 1872-1910). México. Centro de Estudios Históricos - El Colegio de México - UNAM - IIH.

2003 "Morir a manos de una mujer: homicidas e infanticidas en el Porfiriato". En Castro, Felipe - Terrazas, Marcela. Disidencia y disidentes en la historia de México. México. UNAM, pp. 295-321.

2005a "El jurado popular para delitos comunes: leyes, ideas y prácticas (D.F. 1869-1929)". En CÁRDENAS GuTIÉRREZ (coord.), t. II, pp. 743-788.

2005b "Infancia es destino. Menores delincuentes en la ciudad de México (1884-1910)". En Agostini - Speckman Guerra (eds.), pp. 225-253.

2006 "Los jueces, el honor y la muerte. Un análisis de la justicia (Ciudad de México, 1871-1931)". Historia Mexicana. México. n ${ }^{220}$. vol. LV: 4, pp. 1411-1466.

2009 "Ley, lenguaje y ( $\sin$ )razón: abogados y prácticas forenses en la Ciudad de México, 1869-1929)". En Del Arenal - Speckman Guerra (coords.), pp. 349-377.

Teitelbaum, Vanesa E.

2006 "Sectores populares y 'delitos leves' en la Ciudad de México a mediados del siglo XIX”. Historia Mexicana. n 220. vol. LV: 4, pp. 1221-1287.

TéLlez, Mario A.

2009 "La legislación sobre los abogados en el Estado de México del siglo XIX". En Del Arenal- Speckman Guerra (coords.), pp. 241-273.

THOMPSON, Edward P.

1991 The Making of the English Working Class. London. Penguin Books.

Timm Hidalgo, Ana Karina

2010 Entre formalismos y antiformalismos: algunas aproximaciones básicas.

Madrid. Instituto de Derechos Humanos Bartolomé de las CasasUniversidad Carlos III.

URÍAs Horcasitas, Beatriz

$2000 \quad$ Indígena y criminal. Interpretaciones del derecho y la antropología en México, 1871-1921. México. Universidad Iberoamericana.

Zimmermann, Eduardo (ed.)

1999 Law, Justice and State Building. Essays in the History of Judicial Institution in Nineteenth Century Latin America. London. Institute of Latin American Studies and University of London Press. 